\title{
Ultrastructure of the cuticle of the chalimus larva of the salmon louse Lepeophtheirus salmonis (Krøyer, 1837) (Copepoda: Caligidae)
}

\author{
J.E. Bron, A.P. Shinn \& C. Sommerville \\ Institute of Aquaculture, University of Stirling, Stirling FK9 4LA, Scotland
}

Keywords: Lepeophtheirus salmonis, chalimus, Copepoda, cuticle, ultrastructure, parasite

\begin{abstract}
The cuticle of the chalimus II stage of Lepeophtheinus salmonis (Copepoda: Caligidae) comprised a four-layered epicuticle with a pronounced fuzzy coat which was separated from the outer and inner procuticles by a layer of transitional procuticle. The cuticle is underlain by a single-layered epidermis which overlies integumental glands and chromatophores. The structure of this cuticle is very similar to that described for free-living copepods and does not display the modifications associated with more highly transformed parasitic species.
\end{abstract}

\section{Contents}

Introduction

Materials and 39

Results and methods

esults

Epicuticle

Procuticle

Epidermis

Discussion

Summary

Acknowledgements

References

\section{Introduction}

Caligid copepod epizootics attributable to Lepeophtheirus salmonis (Krøyer, 1837) and Caligus elongatus Nordmann, 1832 are now the most important disease problem recognised for marine farmed Atlantic salmon Salmo salar L. in Scotland. Despite this, a lack of information concerning the detailed biology and morphology of these parasites continues to hamper efforts to produce integrated solutions to the problem.
There has been a number of descriptions of the cuticles of free-living, semi-parasitic and parasitic copepods and overviews of these studies have been undertaken by Bresciani (1986) and Boxshall (1992). These studies indicate that the cuticles of copepods are essentially similar to those of other Crustacea. Normally the copepod cuticle comprises a multilayered non-chitinous epicuticle overlying a laminated procuticle. The procuticle comprises an external $p^{1}$ and an internal $p^{2}$ layer. The procuticle overlies a single layered epidermis. The copepod cuticle may become more specialised according to functional requirements, particularly within highly transformed endoparasitic species e.g. Linaresia mammilifera de Zulueta, Lamippe spp. and Gonophysema gullmarensis Bresciani and Lützen (Bouligand, 1966; Bresciani, 1986). The cuticles of parasitic copepods associated with fish hosts have rarely been described, with the only major studies being an ultrastructural description of the cuticle of the pennellid copepod Lernaeocera branchialis (L.) by Smith and Whitfield (1988) and a light microscope study of the cuticle of Caligus savala Gnanamuthu by Kannupandi (1976).

The cuticle of $L$. salmonis provides the principal interface between the organism and its external environment. Amongst other functions it acts as a defence against pathogens / host attacks, constitutes a barrier mediating osmotic and respiratory exchanges and provides a site for support / attachment of the body musculature and internal organs. It is also likely to constitute an important barrier to the action of externally applied pesticides. 
The structure of the cuticle of the attached chalimus larva of $L$. salmonis is described. This description should provide a better understanding of the nature of the cuticle, which is essential for the comparison of larval and adult cuticles. This latter comparison may help explain the apparent lack of sensitivity of attached larval stages of this parasite to a number of pesticides. With the present emphasis on development of in-feed chemotherapeutants and particularly those interfering with moulting / cuticle production, this description will also provide a baseline for later studies concerned with describing the effects of pesticides on cuticle structure.

\section{Materials and methods}

Gravid adult female sea lice were removed from farmed Atlantic salmon and larvae were hatched and reared in the laboratory at $10^{\circ} \mathrm{C}$. Infective copepodids were used to infect 20 Atlantic salmon. Single fish were sacrificed every $24 \mathrm{~h}$ and all attached larval stages removed, perforated to allow fixative penetration and fixed for transmission electron microscopy using the technique of Eisenman and Alfert (1982) modified by omission of the pre-fixative. Chalimus II larvae, present from day 10 to day 18 post-infection, and thereby providing the longest larval interval for examination, were chosen as the subject for this study.

Specimens for TEM were post-fixed in $1 \% \mathrm{OsO}_{4}$, dehydrated through a graded acetone series and embedded in Spurr resin. The resin was polymerised at $70^{\circ} \mathrm{C} .80 \mathrm{~nm}$ sections were cut on a Reichert Ultracut $\mathrm{E}$ and stained with uranyl acetate and lead citrate according to the methods of Hayat (1989) and Reynolds (1963) respectively. The uranyl acetate method was modified by the use of methanol rather than water as the solvent. Grids were observed using a Philips 301 TEM running at $80 \mathrm{KV}$.

The ultrastructure described below is compiled, except where stated, from 1.7 individual larvae considered from TEM observation to have complete (i.e. non-moulting) cuticle morphologies. Measurements are given as ranges or maxima since variation within and between sections of a single individual, let alone between individuals, means that statistical estimates such as means and standard deviations could not be considered representative.

\section{Results}

The cuticle consisted of three recognisable zones (Fig. 1a). These comprised a multi-layered external epicuticle and an internal procuticle comprising two layers; outer and inner procuticle $\left(\mathrm{p}^{1}\right.$ and $\mathrm{p}^{2}$ ). At the interface separating the epicuticle from the $\mathrm{p}^{\mathrm{l}}$ layer was a further distinguishable zone, here termed the "transitional procuticle" (tp1). Underlying the procuticle was a thin epidermis. The cuticle depth varied, being found to attain a maximum depth of $3.6 \mu \mathrm{m}$ for the heavily sclerotised tip of the maxillule and a minimum depth of $0.08 \mu \mathrm{m}$ for the cuticles of the hindgut, foregut and setae. The thickness of the thoracic limb cuticle was also reduced. The cuticle of the dorsal body surface was generally thicker than that of the ventral body surface.

\section{Epicuticle}

A well-defined epicuticle was present in all sections studied (Fig. 1b). The epicuticle was always covered by a fuzzy coat, having the appearance of a mucoid layer. Whilst unstructured in most sections, the fuzzy coat occasionally displayed a structure consisting of a more diffuse electron-lucent surface layer underlain by a more compact and electron-dense inner layer. (Figs. 1a, 1c). The maximum depth attained by this layer was $132 \mathrm{~nm}$. The epicuticle comprised four layers e1-e4 ranging in depth from 80 to $120 \mathrm{~nm}$. The outermost electron-dense layer, e1, presented a maximum depth of $4.5 \mathrm{~nm}$ as did the underlying electronlucent e2 layer. The e3 layer was electron-dense and measured between $9.1 \mathrm{~nm}$ and $13.6 \mathrm{~nm}$. The e4 layer had an electron density intermediate between the $\mathrm{e} 2$ and $\mathrm{e} 3$ layers and displayed a depth of up to $67 \mathrm{~nm}$.

A layer of transitional procuticle (tp1) was situated between the epicuticle and the procuticle. Because it was clearly distinguishable from both overlying and underlying layers, however, and 
despite grading into both at its lower and upper surfaces, it is considered as a separate layer. Whilst layers el-e4 were homogeneous in their appearance, layer tp1 was far more heterogeneous. Normally this layer was more electron-dense than the overlying e4 layer although, on occasion, it was seen to be electron-lucent, which suggests that its composition may vary considerably. Layer tp1 showed no sign of the laminations and fibrous components of the underlying procuticle but often had a granular appearance with electron-dense and/ or electron-lucent inclusions, some of which had the appearance of vesicles (Fig. 1c).

In some body areas, notably the cuticle of the hindgut and foregut, the cuticle of joints and the cuticle of setae, the whole depth of cuticle appeared to comprise epicuticle only or possibly epicuticle and $t p 1$ layers (the latter being indistinguishable). The cuticle in all of these areas is flexible. These areas showed no evidence of the fibrous organisation associated with procuticle. The e3 layer of the hindgut appeared to be expanded in many sections with respect to the e1 and e2 layers (Fig. 1d.). In the areas of hindgut and foregut there were large electron-lucent or electron-dense inclusions within the innermost layer (expanded e4 or tp1) (Fig. 1d.). In the area of the hindgut there were also fine extensions of the cuticle into the epidermis which served to anchor the cuticle in position (Fig. 1e).

In some areas e.g. urosomal somites the cuticle was elaborated with regular crenellations which projected circa $0.9 \mu \mathrm{m}$ from the normal cuticle surface (Fig. 1f.) The crenellations were formed by epicuticle and tpl layer and did not involve the laminated procuticle.

\section{Procuticle}

The procuticle comprised the main part of the cuticle and was up to $2.4 \mu \mathrm{m}$ thick. It was distinguished by the presence of alternating light and dark bands and by the appearance of a fibrous structure through most of its depth. Whilst it was distinguishable into two zones termed $\mathrm{p}^{1}$ (outer procuticle) and $\mathrm{p}^{2}$ (inner procuticle) in some more heavily sclerotised areas (Fig. 1a), it was more usual for the procuticle to have a consistent structural appearance through- out its depth such that $\mathrm{p}^{1}$ and $\mathrm{p}^{2}$ layers were indistinguishable.

The division of the procuticle was most apparent in areas showing heavier sclerotisation such as the tips of appendages e.g. maxillule (Fig. 1a.). In these areas the outer layer $p^{1}$ was more electron-dense than the inner layer and appeared to be composed of successive laminae of electron-lucent batons arranged in a more electron-dense matrix (Fig. 2a). Successive laminae presented either transverse sections or varying longitudinal or semi-longitudinal sections of the batons. The maximum diameter of the electron-lucent batons of the $p^{1}$ layer, in transverse section, was $23 \mathrm{~nm}$.

The underlying $\mathrm{p}^{2}$ layer was more homogeneous (Fig. 1a) but was similarly composed of successive light and dark laminae. The $\mathrm{p}^{2}$ layer was more electron-lucent than the $\mathrm{p}^{1}$ layer. In some sections, vertical stríae were apparent within the laminae of the $\mathrm{p}^{2}$ layer, with wider electron-lucent striae separated by finer, more electron-dense, striae (Fig. 2b). These striae were most apparent in the more electron-lucent laminae but were also present in the electron-dense laminae although more difficult to observe in these areas through lack of contrast. The diameter of the electron-lucent striae was 11$12 \mathrm{~nm}$.

Oblique sections of the $p^{1}$ and $p^{2}$ layers showed a helicoidal architecture (Figs. 2c, 2d). This is indicative of successive laminae of polarised fibres each rotated at an angle to the previous layer. In the $\mathbf{p}^{1}$ layer (Fig. 2c) it is the electron-lucent batons which displayed the helicoidal pattern whilst in the $\mathrm{p}^{2}$ layer (Fig. 2d) the helicoidal pattern comprised very fine electron-dense fibres $(<0.5 \mathrm{~nm})$.

The base of the procuticle in contact with the epidermis was less well organised than the overlying laminated cuticle, often possessing a more granular appearance and having small electronlucent inclusions (Fig. 2e).

Over most of the body cuticle including that of the cephalothoracic shield and pedigerous I urosomal somites, the procuticle was not divided into two distinguishable zones. Instead, the appearance of the procuticle largely corresponded to that of the $\mathrm{p}^{2}$ layer save that the vertical banding described was not usually apparent. Whilst there was normally a more electron-opaque layer overlying 


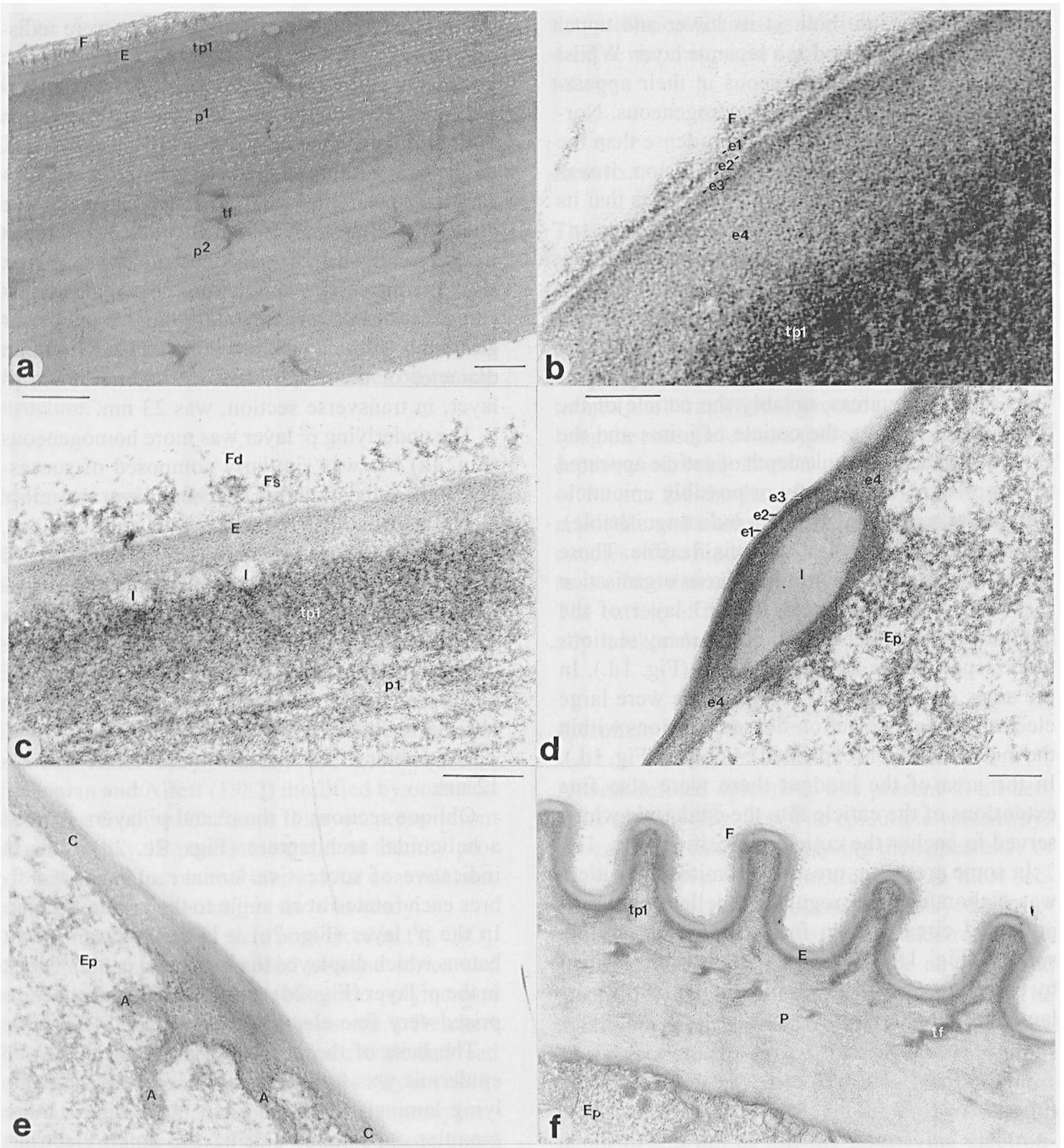

Fig. la. Electron micrograph showing cuticle of tip of maxillule. F Fuzzy Coat; E Epicuticle; $p^{\prime}$ Outer procuticle; $p^{2}$ Inner procuticle; Tf Tonofibril insertions; tp 1 Transitional procuticle. Scale bar $=0.25 \mu \mathrm{m}$

Fig. 1 b. Electron micrograph of epicuticle showing the four identifiable layers. el-e4 Epicuticular layers; F Fuzzy coat; tp1 Transitional procuticle. Scale bar $=25 \mathrm{~nm}$

Fig. $1 c$.Electron micrograph of epicuticle showing a structured fuzzy coat overlying the epicuticle and the transitional procuticle underlying the epicuticle. Fd Diffuse layer of fuzzy coat; Fs Structured layer of fuzzy coat; E Epicuticle; I Inclusion in tp l layer; $\mathrm{pl}$ Outer procuticle; tp1 Transitional procuticle. Scale bar $=0.1 \mu \mathrm{m}$

Fig. Id. Electron micrograph of the hindgut cuticle showing expanded e3 layer and electron-lucent inclusion. Ep Epidermis; el-e4 Epicuticular layers; I Electron-lucent inclusion. Scale bar $=0.25 \mu \mathrm{m}$ 
this procuticle, the structure of this layer appeared to correspond to the tp1 layer. There was no evidence of pigment inclusions within the chalimus procuticle.

\section{Epidermis}

The epidermis comprised a single layer of cells separated from the procuticle by an electron-dense apical membrane which was often elaborated into rugose folds (Fig. 2e).

The epidermal cells were characterised by a high level of activity, based on an abundance of mitochondria and extensive systems of rough and smooth endoplasmic reticulum, with many free ribosomes and vesicles also present in the cytoplasm (Fig. 2e). Certain of the vesicles observed were electron-dense and may represent primary lysosomes. Also present beneath the apical membrane of many cells were abundant microtubules which ran principally parallel to the apical surface.

Less common, but abundant in areas of epidermis where muscles interfaced with the cuticle, were cells corresponding to the tonofibril cells of Bouligand (1962) and "tendinal cells" of Rossner and Sherman (1976). These cells functioned as mediators of attachment between the striated muscles and the cuticle. In these attachments, myofibrils were observed to terminate at extensive zonulae / maculae adherens between the sarcolemma of the muscle and the basal lamina of the tendinal cell. This interface occurred at the level of the $\mathrm{Z}$ band of the myofibril (Fig. 2f). From this interface numerous microtubular tonofilaments measuring $23 \mathrm{~nm}$ traversed the tendinal cell cytoplasm. At the tendinal cell apical membrane, the tonofilaments converged to meet conical invaginations of the membrane. These invaginations formed conical hemidesmosomes measuring from $77 \mathrm{~nm}$ at their basal extremity to $138 \mathrm{~nm}$ at their apical opening (Fig. 3a). The tonofilaments could only be seen around the circumference of the hemidesmosomes and it appeared that they must therefore be attached only to the internal (ie cytoplasmic) surface of the hemidesmosome. The hemidesmosomes formed cups or sockets up to 462 $\mathrm{nm}$ deep. Within these sockets, thick tonofibrils were observed which passed from the socket in the apical membrane into the procuticle. Such connections were best observed in moulting animals where the exuvial cleft had opened to allow visualisation of the transition zone (Fig. 3a). The tonofibrils were homogeneous in their cross-sectional appearance and moderately to highly electron-dense. The diameter of the tonofibrils increased as they passed through the procuticle. At their bases they measured $45-69 \mathrm{~nm}$ whilst they widened in many instances to a diameter of up to $116 \mathrm{~nm}$ as they penetrated the procuticle. Within the procuticle they showed apparent lateral insertions located within the darker laminae (Fig. 3b). Muscles were attached in this manner either to the standard body cuticle or to indented apodemes arising from it. The depth of penetration of tonofibrils into the cuticle was highly variable with insertions seen within both $\mathrm{p}^{\mathrm{l}}$ and $\mathrm{p}^{2}$. The limit of insertion appeared to be the base of the tpl layer, beyond which no tonofibrils were observed to penetrate (Fig. 3c). In areas of reduced cuticle such as the hindgut, the tonofibrils appeared to attach to the base of the epicuticle although it is possible that this basal layer represented undifferentiated tp1 layer (Fig. 2f).

There was no indication of any chromatophores or sub-cuticular secretory cells / glands within the epidermis. Both these cell populations lie beneath the basal lamina of the epidermis (Fig. 3d). Pigmentation within the pigment cells is thought to be provided by large vesicles containing both electron-dense material and electron-lucent needle-like crystals.

\section{Discussion}

The cuticle of $L$, salmonis corresponds to previous descriptions of crustacean, and in particular

\footnotetext{
Fig. Ie. Electron micrograph showing cuticle of hindgut with extensions to aid anchoring within the epidermis. A Anchoring extensions; C Cuticle; Ep Epidermis. Scale bar $=0.2 \mu \mathrm{m}$

Fig. If. Electron micrograph showing crenellated zone of urosomal cuticle. E Epicuticle; Ep Epidermis; F Fuzzy Coat; tpl Transitional procuticle; P Procuticle; Tf Tonofibril insertion. Scale bar $=0.5 \mu \mathrm{m}$
} 


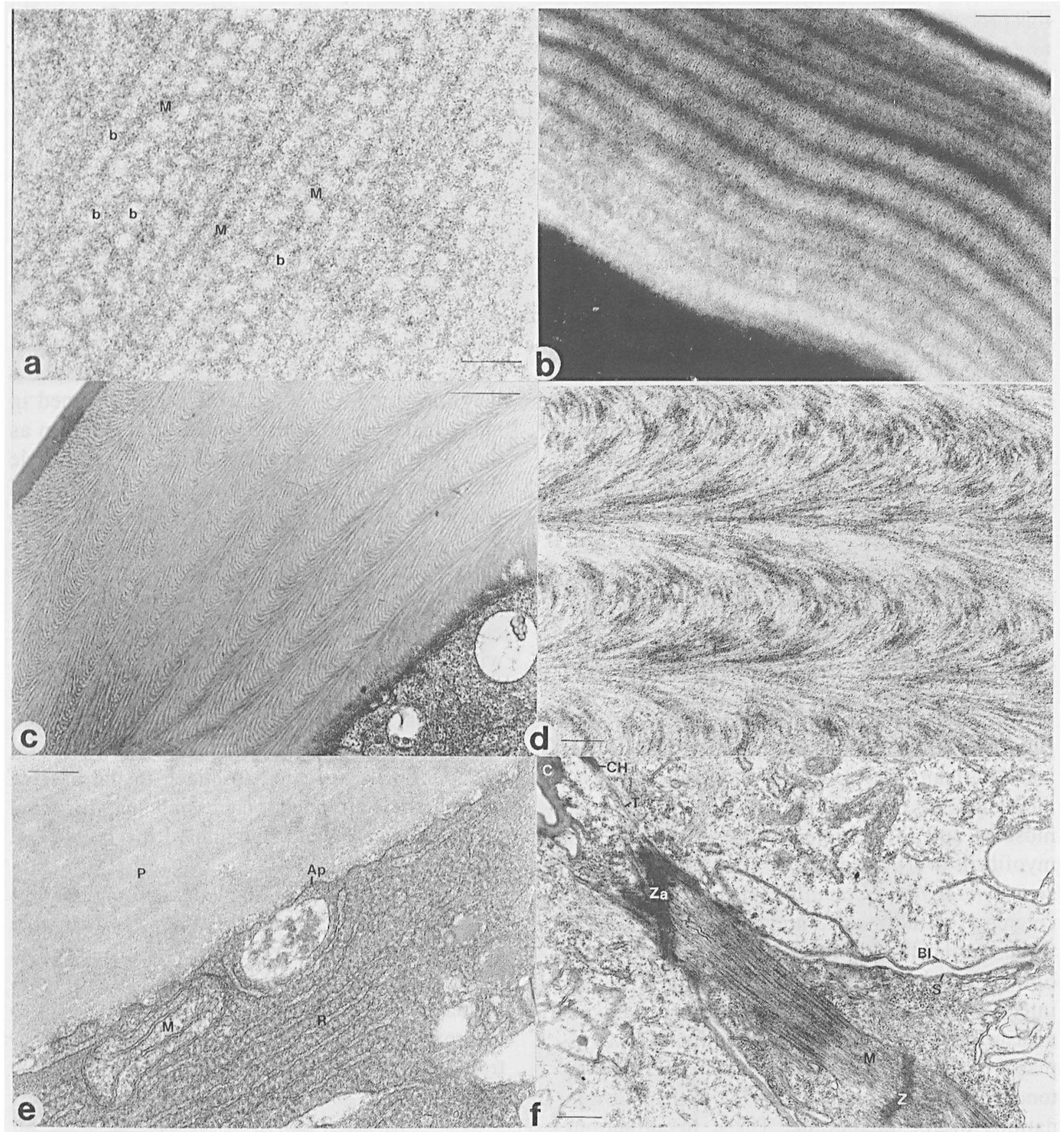

Fig. $2 a$. Electron micrograph showing the structure of the outer procuticle ( $\left.\mathrm{p}^{\prime}\right)$. b Electron-lucent batons; M Electron-dense matrix. Scale bar $=50 \mu \mathrm{m}$

Fig. 2b. Electron micrograph showing the structure of the inner procuticle $\left(\mathrm{p}^{2}\right)$. Light and dark striae are evident, particularly within the lighter laminae of the procuticle. Scale bar $=0.4 \mu \mathrm{m}$

Fig. 2c. Electron micrograph showing oblique section through outer procuticle $\left(\mathrm{p}^{\prime}\right)$ with helicoidal architecture of electron-lucent batons apparent. Scale bar $=0.5 \mu \mathrm{m}$

Fig. $2 d$. Electron micrograph showing oblique section through inner procuticle $\left(\mathrm{p}^{2}\right)$ showing helicoidal architecture of fine fibres. Scale bar $=10 \mathrm{~nm}$

Fig. 2e. Electron micrograph of cuticle and underlying epidermis showing the more granular nature of the basal procuticle and the high activity of the underlying epidermis. Ap Pleated apical membrane; M Mitochondrion; P Procuticle; R Rough endoplasmic reticulum. Scale bar $=0.2 \mu \mathrm{m}$ 


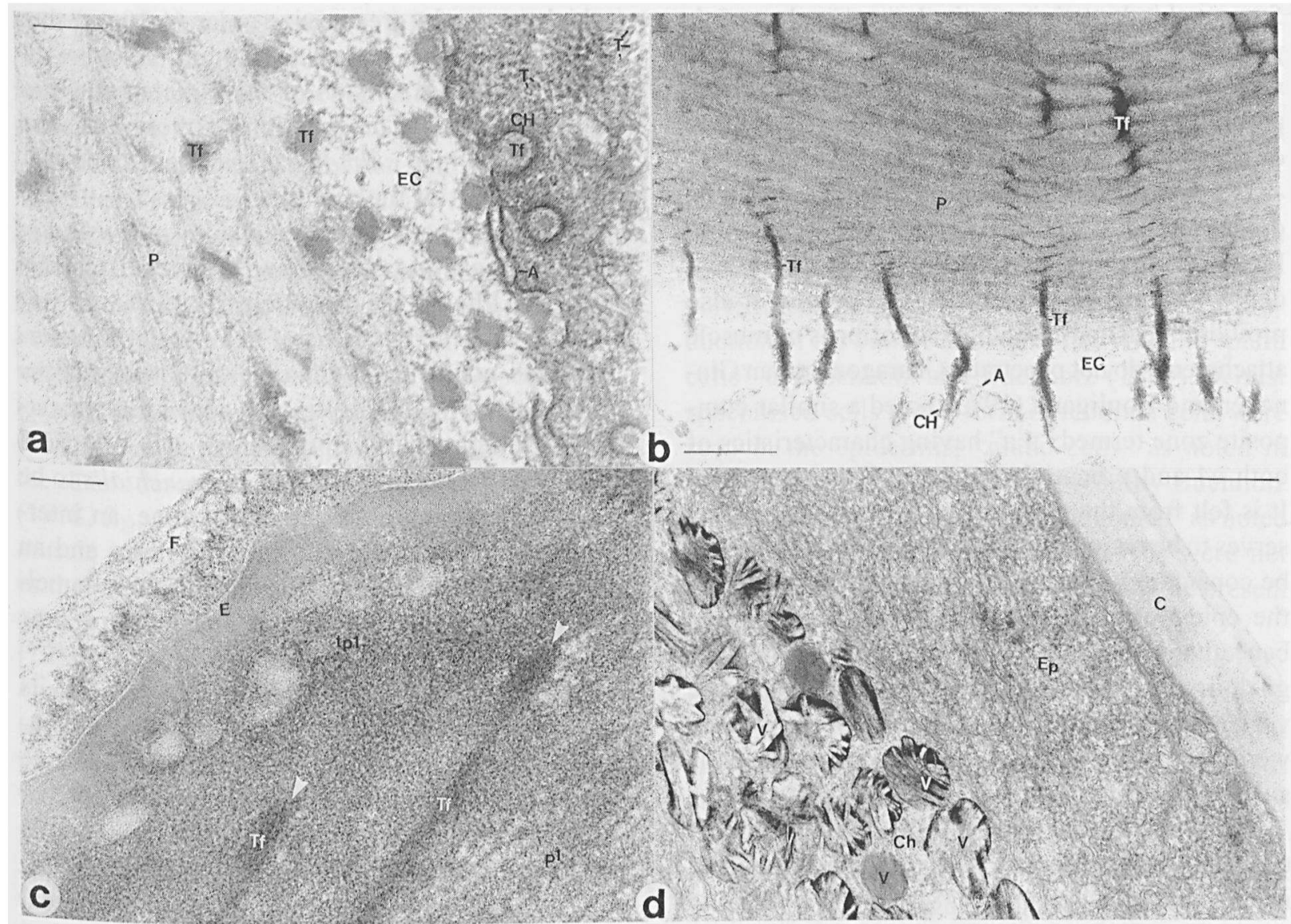

Fig. 3a. Electron micrograph of moulting cuticle illustrating transverse section of tonofibrils passing from conical hemidesmosomes within the tendinal cells across the exuvial cleft and inserting within the procuticle. A Apical membrane of tendinal cell; CH Conical Hemidesmosome; EC Exuvial cleft; P Procuticle; T Tonofilaments; Tf Tonofibril. Scale bar $=0.25 \mu \mathrm{m}$

Fig. $3 b$. Electron micrograph showing insertion of tonofibrils within the procuticle. A Apical membrane of tendinal cell; $\mathrm{CH}$ Conical Hemidesmosome; EC Exuvial cleft; P Procuticle; Tf Tonofibril. Scale bar $=0.5 \mu \mathrm{m}$

Fig. 3c. Electron micrograph showing insertion of tonofibrils (arrowed) at base of transitional procuticle. E Epicuticle; F Fuzzy coat; $\mathrm{p}^{\mathrm{i}}$ Outer procuticle; Tf Tonofibril; tpl Transitional procuticle. Scale bar $=0.1 \mu \mathrm{m}$

Fig. $3 d$. Electron micrograph showing pigment vesicles with crystalline inclusions within a chromatophore located beneath the basal lamina (arrowed) of the epidermis. C Cuticle; Ch Chromatophore; Ep Epidermis; V Pigment vesicle. Scale bar $=0.5 \mu \mathrm{m}$

copepod, cuticles (see reviews by Bresciani 1986 and Boxshall 1992). The epicuticle of L. salmonis mirrors that of the free-living copepods Cletocamptus retrogressus Schmankewitsçh described by Gharagozlou-van Ginneken and Bouligand (1973) and Anomalocera patersoni Templeton described by Bresciani (1986). This structure has also been reported for the semi-parasitic Tisbe holothuriae Humes by Gharagozlou-van Ginneken (1974) and for the parasitic siphonostomatoid Nanaspis ninae Bresciani and Lützen by Bresciani (1986). The epicuticle of L. salmonis is deeper than that of highly transformed parasitic species but is similar to that of $N$. ninae (Bresciani, 1986). The anchoring of the highly flexible hindgut epicuticle seen in $L$. salmonis is likely to function in preventing shearing at the cuticle / epidermis interface. The absence or near absence of procuticle in the areas of

Fig. 2f. Electron micrograph showing attachment of striated muscle to urosomal cuticle. BI Basal lamina of tendinal cell; C Cuticle of urosome; CH Conical Hemidesmosome surrounding tonofibril; M Myofibril; S Sarcolemma; T Tonofilaments; Z Z-band of myofibril; $\mathrm{Za} Z$ onula adherens between sarcolemma at region of Z-band and basal lamina of tendinal cell. Scale bar $=0.5 \mu \mathrm{m}$ 
foregut, hindgut, joint articulations and setae is presumed to confer high flexibility in all of these regions and may also operate to increase permeability to dissolved gases / solutes in the absence of specialised respiratory structures.

The layer described here as tpl deserves to be distinguished from the e4 layer due to its morphological distinction from the e4 layer and its tendency to grade into the procuticle proper. It also provides a barrier past which tonofibrils of muscle attachments do not penetrate. Gharagozlou-van Ginneken and Bouligand (1973) noted a similar composite zone termed " $\mathrm{p}^{1} \mathrm{a}$ " having characteristics of both $\mathrm{e} 4$ and procuticle layers.in $C$. retrogressus. It is felt from the present study that this layer deserves to be recognised separately and that it should be considered as part of the procuticle rather than the epicuticle. Whilst lipid globules were noted beneath the epicuticle of $C$. retrogressus by Gharagozlou-van Ginneken and Bouligand (1973), the vesicles within the tp1 layer of the present study were not usually electron-dense and were not considered to contain lipid.

The fuzzy coat observed to be associated with the epicuticle surface has been previously reported in copepods by Briggs (1978) for Paranthessius anemoniae Claus and by Bresciani (1986) for $A$. patersoni. Briggs demonstrated that the layer contained acid mucopolysaccharide and speculated that it might help function in providing immunity to host nematocyts. It is likely that such coats derive from tegumental glands opening onto the surface and it has been hypothesised (Pochon-Masson, Renaud-Mornant and Cals, 1975; Gharagozlou-van Ginneken, 1979; Hipeau-Jacquotte, 1987; Boxshall, 1982; Bannister, 1993 inter alia.) that such secretions may prevent fouling, deter predators, reduce drag or may function in sexual signalling / recognition. In parasitic species such as $L$ salmonis, secreted material might also function in supression of host immune responses.

Although Briggs (1978) noted that the cuticle of Paranthessius anemoniae was often sculpted into projections which comprised expansions of the epicuticle and procuticle, such ornamentations in L. salmonis comprised the epicuticle and the $\mathrm{tp} 1$ layer of the procuticle only. Smith and Whitfield (1988) noted folds in the cuticle of $L$. branchialis, which were of a greater size order $(4-10 \mu \mathrm{m})$ than those found for $L$. salmonis $(0.9 \mu \mathrm{m})$ and were associated with expansion of the cuticle following the final moult. The function of these cuticular elaborations in L. salmonis is uncertain since they are not a part of the moulting process.

Many copepods appear to display a division of the procuticle into clear $p^{1}$ and $p^{2}$ layers Bresciani (1986). Although the procuticle of $L_{\mathrm{x}}$ salmonis was similarly divided in areas of heavy sclerotisation, this was not usually the case and, instead, the procuticle normally displayed a consistent appearance throughout its depth. Smith and Whitfield (1988) found the procuticle of $L$. branchialis to be organised into an inner laminated zone, an intermediate zone of more disorganised fibres and an outer zone without readily distinguishable lamellae. This outer zone may correspond to the tpl zone described in the present study.

Where a recognisable $\mathrm{p}^{1}$ layer was present, its appearance was identical to that reported by Gharagozlou-van Ginneken and Bouligand (1973) for $C$. retrogressus. The size of the electron-lucent batons recorded in the present study $(\sim 23 \mathrm{~nm})$ agrees extremely well with this previous study $(20 \pm 2.5$ $\mathrm{nm}$ ) suggesting that the batons are of identical provenance. The $\mathrm{p}^{2}$ layer also mirrors that described for $C$. retrogressus. As with the $\mathrm{p}^{1}$ layer, the size of the electron-lucent elements of the two studies also correspond closely (11-12 $\mathrm{nm}$ in the present study and $10 \pm 2 \mathrm{~nm}$ in the earlier study). The basal area of the cuticle lacked the organisation seen in the laminated areas above and is thereby differentiated from the major part of the procuticle. This disorganised basal zone was similarly described by Smith and Whitfield (1988) in L. branchialis.

Whilst Kannupandi (1976) noted a pigmented layer in adult $C$. savala which lay directly beneath the epicuticle, no such layer was recorded in the present study. This difference may reflect the larval nature of the copepod in the present study since large electron-dense inclusions of unknown functional significance have been noted in the procuticle of adult female $L$, salmonis (authors' observations). No pigmented layers have, however, been noted in other copepods thus far studied (Bresciani, 1986).

Many crustacean cuticles possess pore canals such as those described by Goffinet and Compere 
(1986) in Carcinus maenas (L.). Pore canals have rarely, however, been reported in copepods and, where reported, their function and relationship to those of other Crustacea remains obscure. Bresciani (1986: 142) has already noted that whilst pore canals have been reported for "Alteutha, Porcellidium, and Anomalocera amongst free-living species, and from Paranthessius and Linaresia among the parasitic ones", all of these save for those of $P_{x}$ anemoniae studied by Briggs (1978) and A. patersoni studied by Bresciani (1986) do not correspond well to typical pore canals in other arthropods. From evidence in the present study it seems doubtful that the canals described and shown in figures by Briggs (1978, fig. 10: 305) were truly canals rather than muscle insertions. No pore canals were observed in the present study despite reports of their existence in the cuticle of Caligus savala by Kannupandi (1976). They were also absent in the cuticle of $L$. branchialis described by Smith and Whitfield (1988). The only vertical inclusions seen in the present study were the muscle insertions noted within the procuticle. Whilst the pore canals reported in A. patersoni by Bresciani (1986) do not appear to resemble the muscle insertions seen in the present study and elsewhere, they were nevertheless reported by that author to be found "in connection with muscle structures" (Bresciani, 1986: 142). The absence of pore canals, as well as being a general feature of copepods, has also been reported in other Crustacea. One explanation for the absence of canals seen here with respect to their reported presence in adult $C$. savala may be that this study concerns a larval stage. Their absence in larval stages has also been previously reported for the brown shrimp P. aztecus (Talbot, Clark and Lawrence, 1972) and is apparent in photomicrographs of the procuticle of the estuarine crab Rhithropanopeus harrisii (Gould) whose cuticle was described by Christiansen and Costlow (1982). Their absence in the cuticle of Daphnia pulex De Geer and $D$. magna Straus, as described by Schultz and Kennedy (1977) and Halcrow (1976) respectively, was suggested by the latter author to correspond to their general absence in Crustacea with thin cuticles (1-2 $\mu \mathrm{m}$ in the species cited), a group which includes copepods. The same author suggested this feature to be related to a possible re- quirrement for proximity of any given part of the cuticle to the epidermis for the purposes of material exchange (i.e. deposition or absorption).

The epidermis was relatively simple, having a single layer of cells corresponding to most other described copepods. Mytilicola intestinalis, Steuer was, however, described by Durfort (1976) as having one or two layers. The major cell type reported here is thought to be responsible for production of the cuticle and identifies with the "plain cells" of Buchholz and Buchholz (1989). Whilst specialised cells in the form of tendinal cells were seen in the epidermis, "gland cells" as noted in the epidermis of Euphausia superba by Buchholz and Buchholz (1989) and "dermal glands" as noted in C. elongatus by Kannupandi (1976) were not observed. All tegumental glands seen in the present study were located sub-epidermally.

The mode of muscle insertion follows the general pattern described for both copepods (e.g. Bouligand, 1962) and other Crustacea such as crabs (Rossner and Sherman, 1976) and euphausids (Buchholz and Buchholz 1989). Although Briggs (1978) suggested that the tonofilaments of $P$. anemoniae passed between the epidermal cells it is clear from his figures that they probably traversed the epidermal cells as in the present study. There were, however, some differences between the findings of the present study and previous studies on Copepoda. Whilst most features of the muscle attachment reported here correspond to those described by Bouligand (1962) for Cyclops spp., no evidence could be demonstrated for a direct connection between the tonofilaments, which traverse the tendinal cells, and the tonofibrils which pass from the socket provided by invaginations of the apical membrane and associated hemidesmosomes into the procuticle. It seems likely that the attachments of $L$. salmonis mirror more closely those of the larval brown shrimp $P$. aztecus described by Talbot, Clark and Lawrence (1972), although the intracuticular rods of that study were not observed here and neither were free-ending tonofilaments. The structure also corresponds to that described by Rossner and Sherman (1976) for the muscle " insertions of $C$. maenas and indeed the diameter of tonofilaments seen in that study $(24 \mathrm{~nm})$ is almost identical to that reported here $(23 \mathrm{~nm})$ sug- 
gesting a very close alliance between structural components. The size of the tonofibrils recorded here also corresponds well to those of $C$. maenas. It has been suggested that the direct embedding of tonofibrils within the cuticle observed in larval animals might be superseded by the passage of these fibres through pore canals in adult stages (Talbot et al., 1972) although this suggestion has yet to be supported by further observations of the present species. The tonofibrils in $L$. salmonis did not extend into the epicuticle as they have been suggested to do in the crayfish Orconectes limosus (Rafinesque) by Kümmel, Claassen, and Keller (1970) but were observed to reach only as far as the lower edge of the tpl layer.

As noted earlier, some of the structures suggested to be pore canals in other papers appear to represent continuations of the muscle insertions within the procuticle as for the "vertical canals" of $P$. anemoniae described by Briggs (1978). Part of the reason for the confusion is the appearance of branching of the tonofibrils in some species e.g. those of larval brown shrimp $P$, aztecus described by Talbot et al.(1972) which mimics the branching of pore canals reported for adults of decapod species such as the fiddler crab Uca pugnax (Smith) described by Green and Neff (1972). Whilst it appears in this and other studies (e.g. Briggs, 1978) that the tonofibrils give out lateral insertions within the electron-dense bands of the procuticle, it is likely that this, in the same way as the appearance of the light / dark banding of the procuticle, is an artefact of the sectioning of fibrils in different orientations.

\section{Summary}

This paper describes the ultrastructure of a caligid cuticle for the first time and indicates it to have more in common with the cuticle of free-living copepods than with those of more transformed parasitic species. Whilst the results apply to a single stage, they form the basis for further studies which may elucidate any differences that exist between larval and adult / preadult cuticles and may serve to help explain the differences in sensitivity to pesticides that are observed.

\section{Acknowledgements}

The authors wish to express their thanks to all the salmon farms in Scotland who have provided material for study and without whom this work could not be carried out. We should also like to thank Maureen Menzies and Marguerite Kobs for their irreplaceable technical expertise and assistance and Obdulio Andrade-Salas for his comparative work with adult sea lice. This work was carried out as part of a project funded by MAFF CSG for whose financial assistance we are indebted.

\section{References}

Bannister NJ. 1993. Distribution and structure of sub-cuticular glands in the copepod Temora longicomis. J. Mar. Biol. Ass. U.K. 73: 97-107.

Bouligand Y. 1962. Les ultrastructures de muscle strié et de ses attachés au squelette chez les Cyclops (Crustacés Copépodes). J. Microsc. 1: 377-394.

Bouligand Y. 1966. Le tégument de quelques Copépodes et ses dépendances musculaires et sensorielles. Mém. Mus. Natl. Hist. Nat. (Paris) Série A XL: 189-206.

Boxshall GA. 1982. On the anatomy of the misophrioid copepods, with special reference to Benthomisophria palliata Sars. Phil. Trans, Roy. Soc, Lond., B 297: 125-181.

Boxshall GA. 1992. Copepoda. Chapter 7 in: Microscopĩc Anatomy of Invertebrates 9: Crustacea. Wiley-Líss, Inc. 347-384.

Bresciani J. 1986. The fine structure of the integument of free-living and parasitic copepods. A review. Acta Zool. 67(3): 125-145.

Briggs, R.P. 1978. Structure of the integument in Paranthessius anemoniae Claus, a copepod associate of the Snakelocks anemone Anemonia sulcata (Pennant). J. Morph. 156: 293315.

Buchholz C, Buchholz F. 1989. Ultrastructure of the integument of a pelagic crustacean: Moult cycle related studies on the Antarctic krill Euphausia superba. Mar. Biol. 101(3): 355-365.

Christiansen ME, Costlow JD Jr. 1982. Ultrastructural study of the exoskeleton of the estuarine crab Rhithropanopeus harrisi: Effect of the insect growth regulator Dimilin ${ }^{\infty}$ (Diflubenzuron) on the formation of the larval cuticle. Mar. Biol. 66: 217-226.

Durfort M. 1976. Estructura y ultraestructura del tegumento de Mytilicola intestinalis, Steuer (Crustacea: Copepoda). Misc. Zool, 3: 69-77.

Eisenman EA, Alfert M. 1982. A new fixation procedure for preserving the ultrastructure of marine invertebrate tissues. J. Microsc. 125: 117-120.

Gharagozlou-van Ginneken ID. 1974. Sur l"ultrastructure cuticulaíre d'un crustacé copépode harpacticide; Tisbe holothuriae Humes. Arch. Zool. Exp. Gén. 115: 411-422.

Gharagozlou-van Ginneken ID. 1979. Étude ultrastructurale et cytochimique de l'activité temporaire des glandes tégu- 
mentaires d'un crustacé copépode. Ann. Scí. Nat. Zool, Par., serie 13: 205-212.

Gharagozlou-Van Ginneken ID. Bouligand Y. 1973. Ultrastructures tégumentaires' chez un crustacé copépode Cletocamptus retrogressus. Tissue Cell 5: 413-439.

Gnanamuthu CP. 1948. Notes on the anatomy and physiology of Caligus savala, a parasitic copepod from Madras plankton, Proc. Zool. Soc. Lond, 118: 591-606.

Goffinet G. Compere P. 1986. Pore canals and organization of the chitinoproteins in the cuticle of the crab Carcinus maenas. In: Muzzarelli R, Jeuniaux C, Gooday G, eds. Chitin in Nature and Technology. New York: Plenum Press.

Green JP, Neff MR. 1972. A survey of the fine structure of the integument of the fiddler crab. Tissue Cell 4: 137-171.

Halerow $K, 1976$. The fine structure of the carapace integument of Daphnia magna Straus (Crustacea Branchiopodia). Cell Tissue Res. 169: 267-276.

Hayat MA. 1989. Principles and Techniques of Electron Microscopy-Biological Applications. 3rd Edition. Basingstoke and London: Macmillan Press Scientific and Medical.

Hipeau-Jacquotte R. 1987. Ultrastructure and presumed function of the pleural dermal glands in the atypical male of ther parasitic copepod Pachypygus gibber (Crustacea: Notodelphidae), J. Crust. Biol. 7: 60-70.

Kannupandi T. 1976. Cuticular adaptations in two parasitic copepods in relation to their modes of life. J. Exp. Mar Biol. Ecol. 22: 235-248.
Kümmel G, Claassen H, Keller R. 1970. Zur Feinstruktur von Cuticula und Epidermis beim Flusskrebs Orconectes limosus während eines Hautungszyklus, Z. Zellforsch. 109; 517-551.

Pochon-Masson J, Renaud-Mornant J, Cals P. 1975. Contribution a la connaissance des glandes tégumentaíres métamériques d'un crustacé meỉobenthique interstitiel (Crustacea: Mystacocarida). Cytologie structurale et infrastructurale. Arch. Zool. Exp. Gèn. 116: 123-146.

Reynolds ES. 1963. The use of lead citrate at high $\mathrm{pH}$ as an electron opaque stain in electron microscopy. J. Cell Biol. 17: 208.

Rossner KL, Sherman RG. 1976. Organization of a skeletal muscle insertion in the crab Carcinus maenas. Trans. Am. Microse. Soc. 95: 46-55.

Schultz TW, Kennedy JR. 1977. Analyses of the integument and muscle attachment in Daphnia pulex (Cladocera: Crustacea), J. Submicrose. Cytol. 9: 37-51.

Smith JA, Whitfield PJ. 1988. Ultrastructural studies on the early cuticular metamorphosis of adult female Lernaeocera branchialis (L.) (Copepoda, Pennellidae). Hydrobiologia 167/168: 607-616.

Talbot P, Clärk WH, Lawrence AL. 1972. Ultrastructural observations of the muscle insertion and modified branchiostegite epidermis in the larval brown shrimp, Pennaeus aztecus. Tissue and Cell 4: 613-628.

Received: 1 February 1999 